\title{
MENTAL HEALTH LITERACY AMONG THE SOCIETY IN SURAKARTA
}

\author{
Setia Asyanti, Usmi Karyani \\ Faculty of Psychology, Universitas Muhammadiyah Surakarta
}

\begin{abstract}
Background: Mental health literacy refers to knowledge and beliefs about mental disorders which assists individuals in recognizing, managing, and preventing mental disorders. However, little is known about mental health literacy among the society in Surakarta, Central Java, Indonesia. This study aimed to describe mental health literacy among the society in Surakarta.

Subjects and Method: This was a descriptive quantitative study conducted in Surakarta, Central Java. A total of 288 people were selected for this study. The data were collected using questionnaire with the concept of mental health literacy from Jorm. The data were analyzed using descriptive analysis.

Results: Mental health literacy among the society in Surakarta showed: 1) the community had not comprehensively understood mental disorders; 2) the community identified 1 factor as a cause of mental disorders; 3) people better recognized behavioral symptoms than other symptoms of mental disorders; 4) people relatively understood early treatment in people with mental disorders through social support; 5) the community understood prevention of mental disorders even though they are still in the form of partial without concrete actions.
\end{abstract}

Conclusion: Mental health literacy among the society in Surakarta is yet to be improved.

Keywords: mental health, literacy, society

Correspondence:

Setia Asyanti. Faculty of Psychology, Universitas Muhammadiyah Surakarta, Surakarta, Central Java. Email: setia.asyanti@ums.ac.id. Mobile: 08156724493.

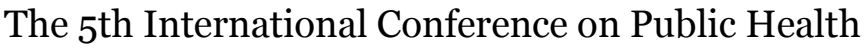

Best Western Premier Hotel, Solo, Indonesia, February 13-14, 2019 | 172

https://doi.org/10.26911/theicph.2019.02.17 